\title{
Stupor mundi
}

\author{
Erhard Taverna
}

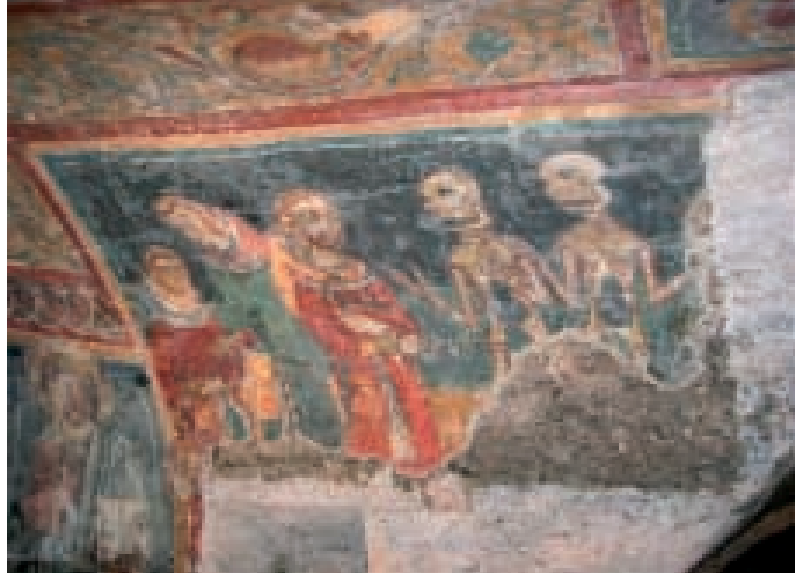

Schwarze Wolkentürme schleudern Blitze und Regenböen auf die Hügelstadt unter der Normannenburg. Dann reisst blendend der Himmel auf, und die nassen Steine von Melfi sprühen und funkeln. Es riecht plötzlich nach Weihrauch, Minze und Rosmarin. Der Ort ist nicht von ungefähr ein beliebtes Kongressziel für Gerichtsmediziner. «Und so, durch notwendigen Zwang der Dinge selbst und nicht minder durch Antrieb der göttlichen Vorsehung, wurden die Fürsten der Völker gewählt,» damit die Freiheit zu Verbrechen eingeschränkt werden könnte, und sie, über Leben und Tod entscheidend, gleichsam als Vollstrecker der göttlichen Vorsehung, jedem das ihm gebührende Schicksal, seinen Stand und Anteil begründen sollten.» So verkündet es der erhabene Caesar, König Siziliens, Messias und Antichrist, der Hammer der Erde, Friedrich II., selbstberufener Hüter, der durch den Sündenfall gestörten Ordnung. Die 1231 verkündeten Konstitutionen kodifizieren Staats- und Verwaltungsrecht, darunter erstmals Gesetze zum Schutze der Umwelt und zur öffentlichen Gesundheit. Rom, Byzanz und das bestehende Recht der normannischen Eroberer liefern die Bausteine. Neu sind der imperiale Anspruch und der Aufbau eines modern anmutenden Beamtenstaates, der umfassend das tägliche Leben regelt. Mit den Mitteln des Straf- und Berufsrechtes, mit Gesetzen zur Abfallentsorgung, mit Zöllen und Monopolen, Friedhofsreglementen und Bordellvorschriften. Und natürlich Steuern und Abgaben und Kontrollen. Den Heilberufen gilt seine besondere Aufmerksamkeit:
Drei Jahre Logik und danach fünf Jahre Medizin, mit Praktikum unter erfahrener Aufsicht, dazu Studium der Chirurgie und Anatomie. Kerker für jeden, der ohne kaiserliche Approbation Patienten behandelt. Das Kurieren ist strikte getrennt vom Herstellen und Vertreiben der Medikamente. Die Giftgesetze verraten den aufgeklärten Skeptiker. Das Verbot von Liebestränken macht das Strafmass von den Folgen abhängig und zielt auf die Gesinnung: «Und obwohl denen, die die Wahrheit und die Natur der Dinge beobachten, dies nichtig und fabelhaft erscheinen dürfte, dass der Sinn des Menschen durch Speisen oder Getränke bewegt werden kann [...], so wollen wir doch die leichtfertige Anmassung mit der sie mindestens zu schaden wünschen, wenn sie auch nicht schaden können, nicht ungestraft dahingehen lassen.»

Schafe, Heilige und Schiffe bestimmen bis heute das industrielle Schicksal der Capitanata im Norden Apuliens. Zum steinigen Gargano kommen seit je die Pilger, zum Stier Michaels des Erzengels in der Grotte, «ubi saxa panduntur ...», oder in die Nachbargemeinde zu Padre Pio, wo Renzo Piano den Millionenscharen die weltgrösste Kuppel baut. Sie bringen mehr Gewinn als der Export streitsüchtiger Kreuzritter, «des Adelspackes, das sich», gemäss Bernhard von Clairvaux, dem Ordensgründer, «in Jerusalem bewähren soll.»

Unten in der Ebene glänzt nass die schwarze Ackererde bis zum Horizont. Hügelauf und hügelab führt schnurgerade die Ackerspur, kilometerweit durch die Tavoliere, wo grün die Wintersaat für Italiens Pasta sprosst. An den Schuhen klebt der aufgeweichte Wanderweg, die Strassen sind schlammig überflutet. Kein Mensch weit und breit, in der ausgeräumten Landschaft nur zerfallene Gehöfte, aus den faschistischen Zeiten der Trockenlegung von Sümpfen und die Mauerreste einer Masseria aus der Stauferzeit, zisterziensischer Musterbetrieb auf königlichem Grundbesitz. Hier war immer Kornkammer, Landflucht und Wassernot, trotz Leitungen aus dem Apennin. Berlusconi reist an die Fiera del Levante im nahen Bari. Die 67. Industrie- und Landwirtschaftsmesse sucht neue Absatzgebiete und entdeckt den Osten. Alles, wie gehabt. Für das alte Südreich lag Konstantinopel näher als Mailand. Alle Häfen sind von Kathedralen und Festungen 


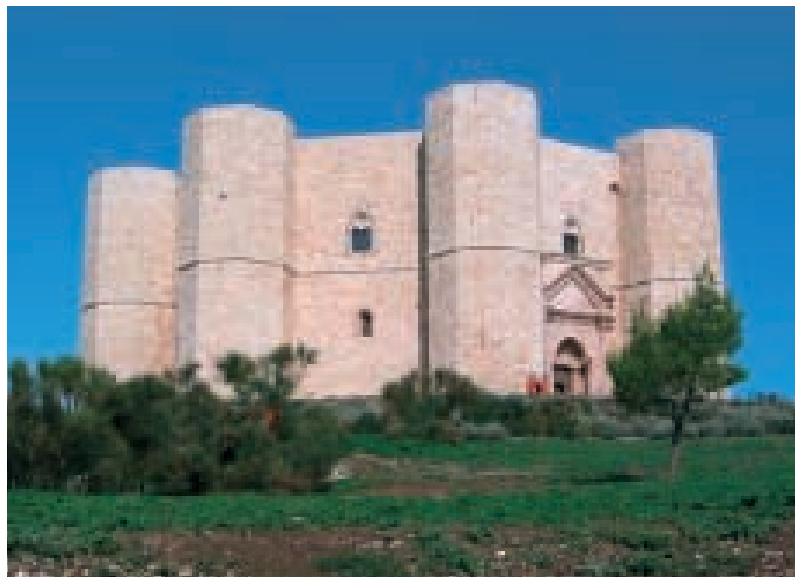

eingerahmt. Die Wanderung endet in der Dämmerung vor einem kahlen Hügel. Vom Castel Fiorentino sind wenige Reste auszumachen. Friedrich II. starb hier 56jährig im Dezember 1250. Bellende Hunde treiben eine Schafherde zusammen. Der Hirt singt einen Belcanto für die ersten Sterne. Er singt gut.

Vom Jagdschloss Garagnone geht der Blick in das weite, stille Land. Ein Falkenpaar streitet mit einem Habicht. Mannshohe, dürre Fenchelstengel und Herbst-Goldbecher umgeben den Berg. Nach einem gewundenen Talweg durch verkarstete Hügel sind wir wieder auf der Hochebene. Weit entfernt liegt über einem bewaldeten Hügel Castel del Monte. Einige Panzer bewachen nahe Funkanlagen. Steinmauern und Hecken säumen den Weg, kleine Pinienwälder und Steineichen, Oliven und Feigen. Das dürre Gras raschelt unter den Füssen, auf dem Spargelkraut lauert die Gottesanbeterin. Vögel ernten Schlehdorn und Hagebutten. Die Schatten der vielen Trulli werden länger, der ferne Bau liegt wie eine Krone über dem Land.
Vor dem blauen Morgenhimmel strahlt goldgelb der Kalkstein der Mauern. Eine Variation zum Achterthema: ein achteckiger Grundriss mit oktogonalen Ecktürmen, ein achteckiger Innenhof, acht Säle im Erd- und Obergeschoss. Ein erhabener Bau, der stumm zu umrunden ist, bevor man ihn durch das mit rot-weisser Korallenbrekzie umfasste Portal betritt. Ein steinernes Buch mit einem verschlüsselten Text. Jede Kante und jede Mauer eine astronomische Uhr, ein kosmisches Zeichen, ein mathematisches Spiel mit Fibonacci-Zahlen und dem Goldenen Schnitt. Keine Festung, aber was sonst? Den Esoterikern ein Tempel, für alle Forscher ein Labyrinth aus Fakten und Spekulationen. Der von Hohenstaufen hat es geplant, aber nie bewohnt. Er, der Masslose, der rastlose Feldherr gegen Papst und Lombardei, der Bauherr deutscher Pfalzen, romanischer Kathedralen und Burgen, der Medizin und Diäten Geneigte, Universitätsgründer, Gesetzgeber, Astronom und Vogelkenner. Polyglott und fruchtbar war er auch, liess Bücher übersetzen, schuf Minnelyrik und eine Volkssprache und zeugte nebenbei noch 15 Kinder mit 11 Frauen. Ein Kenner der Sarazenenwelt, der dem Sultan Merlins Zaubersprüche übersetzen liess. Universalmensch, tief im Mittelalter und schon halb in der Renaissance. Nichts ist hier zufällig gemauert, alles ist durchdacht, wie die Gesetze von Melfi, wie das Falkenbuch, wie das Latein der Kanzlei von Palermo. Das Ende kam schnell und brutal. Der Bau wurde den Enkeln zum Kerker, dem Geschlecht der Staufer zum Grabstein. Der italienische Staat hat 1876 die Ruine über dem Wald von Ruvo für einen Spottpreis gekauft und viel später vorbildlich renoviert. Zu Recht gilt heute Castel del Monte als das Symbol für die faszinierendste Gestalt eines bedeutsamen Jahrhunderts europäischer Geschichte. 